\title{
JET PUMP SEBAGAI POMPA HAMPA
}

\author{
Daru Sugati \\ Jurusan Teknik Mesin STTNAS Yogyakarta \\ Jl. Babarsari No.1.Depok, Sleman, Yogyakarta, Telp.0274.485390 \\ Email:daru_wates@yahoo.com
}

\begin{abstract}
ABSTRAK
Penelitian ini bertujuan untuk menemukan karakteristik sebuah jet-Pump yang difungsikan sebagai pompa hampa atau vakum. Sebagai fluida primer atau motive fluid digunakan air dan fluida sekunder digunakan udara. Parameter yang diteliti adalah hubungan debit aliran sekunder terhadap derajat kevakuman dan efisiensi jet pump pada berbagai variasi variasi $L_{t h} / d_{\text {th }}$ bervariasi 9,7, dan $5, S_{n}$ bervariasi 1, 1.5, dan 2 á $=15^{\circ}$, serta tekanan Motive fluid bervariasi $228 \mathrm{~cm} \mathrm{Hg}, 190 \mathrm{~cm} \mathrm{Hg}$, $152 \mathrm{~cm} \mathrm{Hg}$. Hasil penelitian menunjukkan hubungan yang signifikan antara debit aliran vakum terhadap derajat kevakuman. Debit aliran vakum cenderung menunjukkan penurunan terkolelasi dengan menurunya tekanan sisi sekuder. Efisiensi maksimum terjadi pada tekanan motive $228 \mathrm{~cm} \mathrm{Hg}, S_{n}=2$, dan $L_{t h} / d$ th $=9$ dan $M=0,32$ yaitu sebesar 13,5
\end{abstract}

Kata Kunci: Jet pump, pompa hampa, nosel, throat.

\section{PENDAHULUAN}

Jet Pump adalah sebuah alat yang mampu memberikan beda tekanan fluida sehingga fluida mampu mengalir tanpa menggunakan bagian yang bergerak. Keunggulan dari jet pump menjadikan alat ini digunakan untuk mengalirkan fluida dalam berbagai fase. Komponen utama jet pump terdiri dari nosel, throat, difuser dan ruang pencampur atau ruang induksi, seperti terlihat pada Gambar 1.

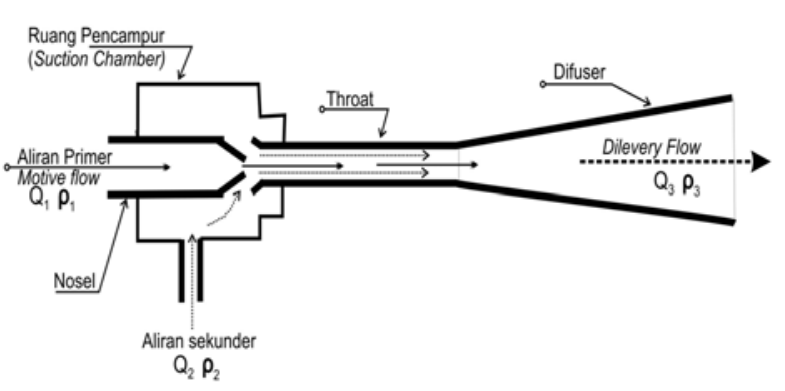

Gambar 1. Skema Jet Pump
Kinerja jet pump dipengaruhi oleh konfigurasi dari komponen utama tersebut. Untuk menyatakan unjuk kerja dari sebuah jet pump dinyatakan dengan parameter efisiensi. Pengujian beberapa konfigurasi jet pump akan memberikan karakteristik yang berbeda. Jet pump sebagai pompa vakum adalah jet pump yang difungsikan sebagai alat untuk memvakumkan ( memberikan tekanan dibawah tekanan atmosfir ) melalui sisi aliran sekundernya.

Penelitian tentang jet pump untuk aliran cair-cair sudah lama dan banyak dilakukan para peneliti. Stepanoff (1957) menjelaskan faktor yang mempengaruhi efisiensi jet pump. Ada beberapa faktor utama yang mempengaruhi efisiensi jet pump yakni: Pertama, rasio luas penampang nosel (R) dan throat yaitu efisiensi terbesar didapat pada $\mathrm{R}=0.28$ yang besarnya $35 \%$. Kedua, adalah fungsi bilangan Reynolds dalam hal ini pengaruh viskositas dimana semakin besar bilangan Reynolds maka efisiensi semakin naik. 
Penelitian yang dilakukan telah memberikan gambaran bahwa efisiensi jet pump dipengaruhi oleh beberapa parameter. Beberapa penelitian yang telah dilakukan tidak menggunakan udara sebagai fluida pada sisi sekunder. Pada penelitian ini dilakukan pengujian dengan menggunakan udara sebagai fluida pada sisi sekunder.

Teori jet pump dikembangkan dari teori Bernoulli. Tekanan statis pada saluran masuk nosel dikonversikan menjadi energi kinetik dengan membiarkan cairan mengalir secara bebas melalui sebuah nosel tipe konvergen. Aliran yang berkecepatan tinggi mengangkut fluida masuk ke daerah pencampuran sehingga menghasilkan fluida campuran pada kecepatan menengah. Sisi difuser kemudian mengkonversikan head dinamik kembali menjadi tekanan statis pada ujung jet pump.

Indikator yang dipakai untuk menyatakan unjuk kerja adalah efisiensi jet pump terhadap beberapa besaran lain. Besaran besaran nondimensional yang dipakai pada pengujian jet pump adalah:

1. Rasio luas penampang antara nosel dan throat, $R=A_{n o} / A_{\text {th }}$

2. Rasio kapasitas aliran sekunder dan primer, $M=Q_{2} / Q_{1}$

3. Rasio tekanan, $N=\left(P_{d}-P_{s}\right) /\left(P_{i}-P_{d}\right)$

4. Rasio kecepatan, $\bar{V}=\left(V_{2 o} / V_{1 o}\right)=M R(1-R)$

5. Rasio luas penampang difuser, $\mathrm{a}=A_{t h} / A_{d i}$

\section{METODE PENELITIAN}

Penelitian ini merupakan penelitian ekperimen, skema instalasi pengujian, tampak pada Gambar 2.

Variasi pengujian yang dipakai adalah perubahan spasi nosel $\left(\mathrm{S}_{\mathrm{n}}\right)$, perubahan tekanan motive, rasio diameter troat terhadap panjangnya $\left(\mathrm{L}_{\mathrm{th}} / \mathrm{d}_{\mathrm{th}}\right)$. Proses penelitian mengikuti prosedur seperti yang tersaji pada Gambar 3.a. dan Gambar 3.b.

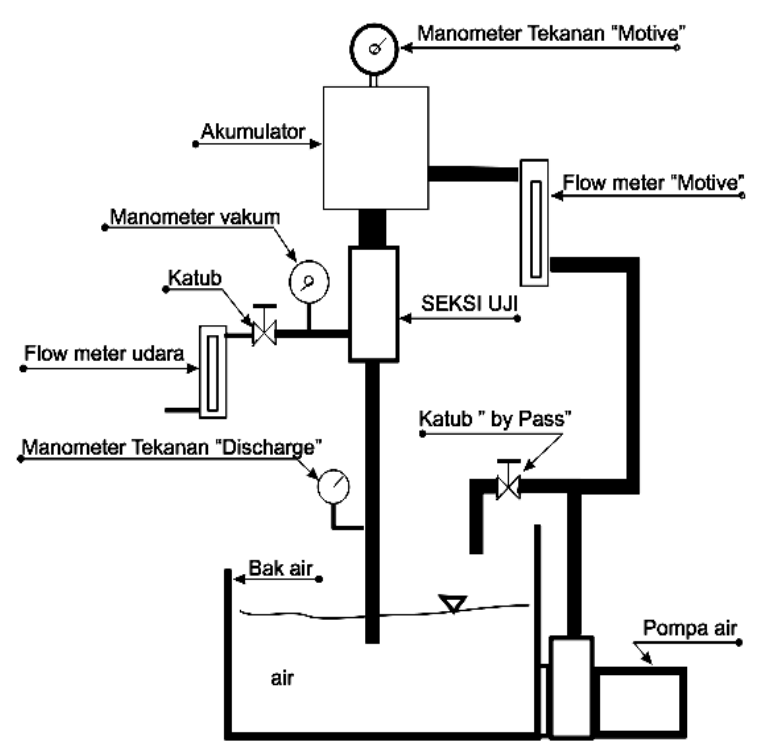

\section{Gambar 2. Skema Instalasi Penelitian}

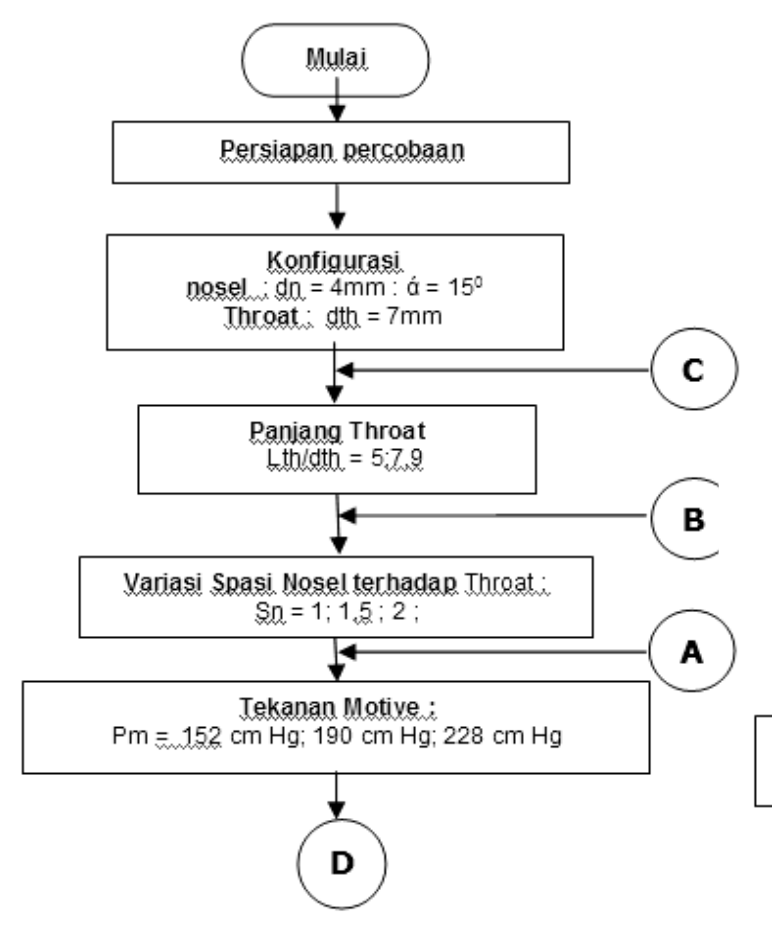

Gambar 3.a. Diagram Alir Proses
Penelitian 


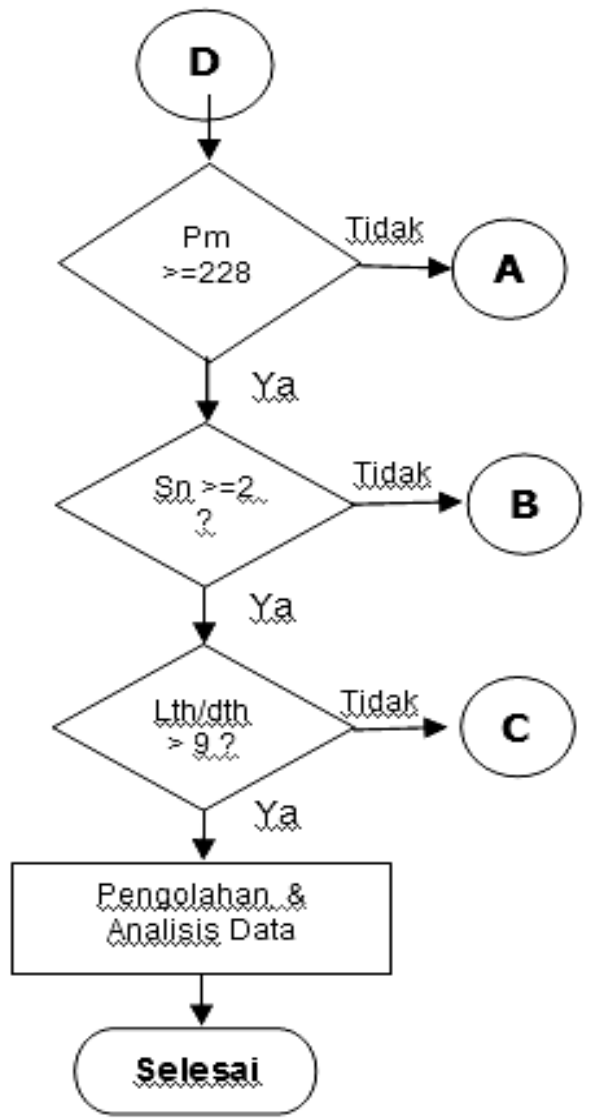

Gambar 3.b. Diagram Alir Proses Penelitian

\section{HASIL DAN PEMBAHASAN}

Gambar 4. hingga Gambar 19 menyajikan grafik-grafik hasil pengukuran pada ekperimen.

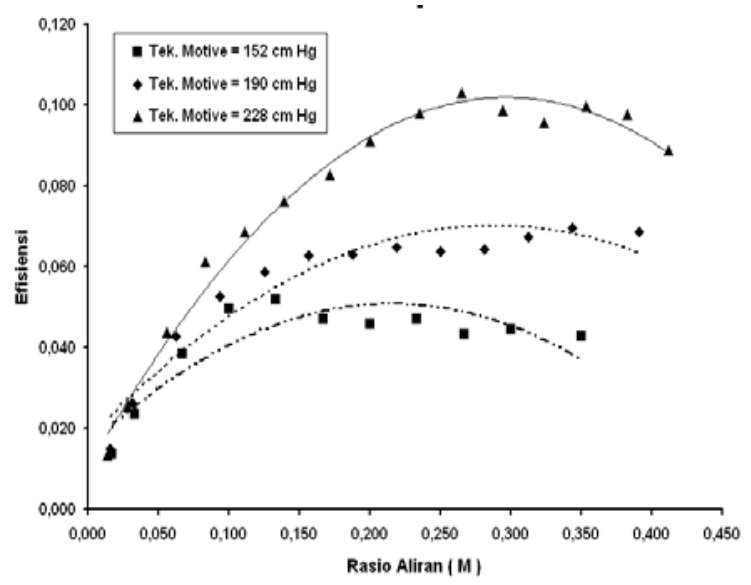

Gambar 5. Hubungan Efisiensi terhadap Rasio Aliran (M) pada $S_{n}=1, L_{t h} / d_{t h}=9$ dan

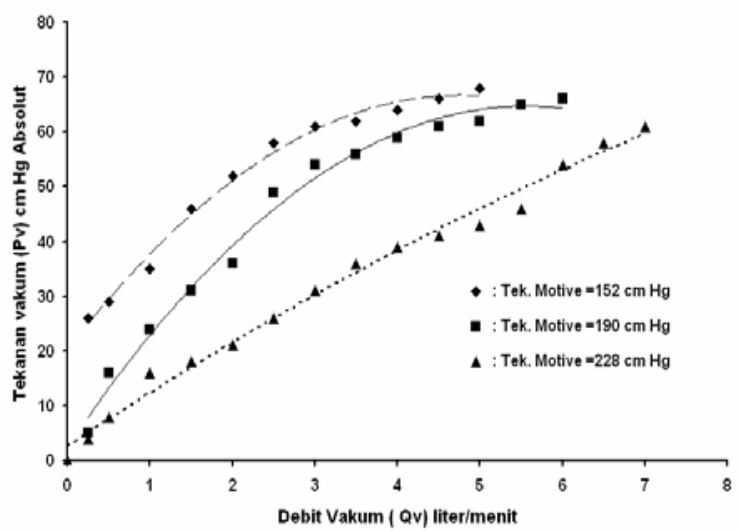

Gambar 6. Hubungan Tekanan Vacum $\left(\mathbf{P}_{\mathrm{v}}\right)$ terhadap DebitAliran $\left(Q_{v}\right)$ pada $S_{n}=2, L_{t h} / d_{t h}=9$

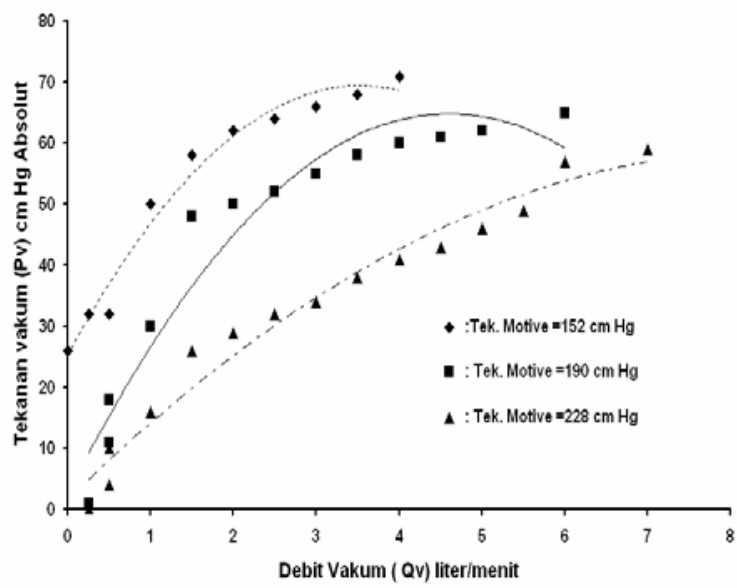

Gambar 7. Hubungan Tekanan Vacum $\left(P_{v}\right)$ terhadap Debit Aliran $\left(Q_{v}\right)$ pada $S_{n}=1, L_{\text {th }} /$ $d_{t h}=7$, dan á $=15^{\circ}$. 


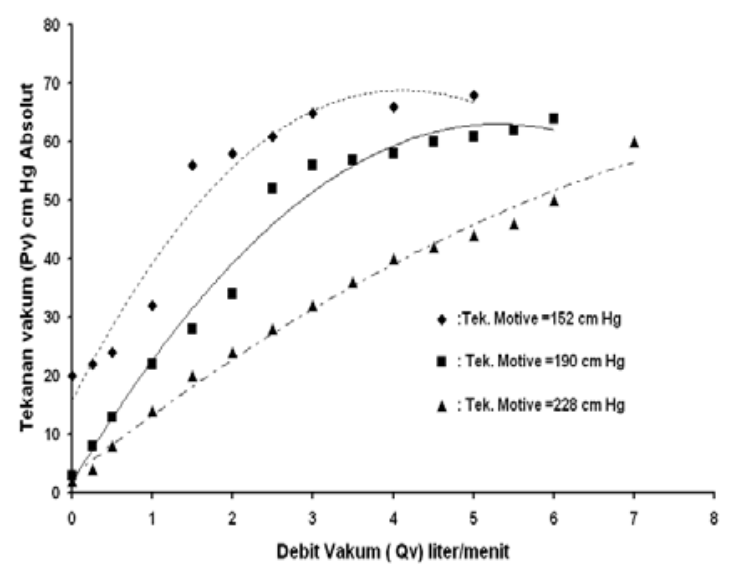

Gambar 8. Hubungan Efisiensi terhadap Rasio Aliran (M) pada $S_{n}=1, L_{t h} / d_{t h}=7$

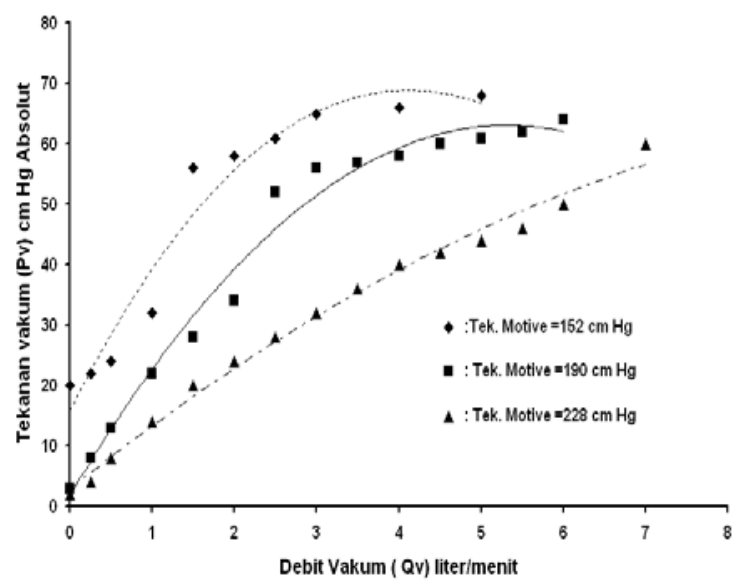

Gambar 9. Hubungan Tekanan Vacum $\left(P_{v}\right)$ terhadap Debit Aliran $\left(Q_{\mathrm{v}}\right)$ pada $S_{n}=\mathbf{2}, L_{t h} /$

$$
\mathrm{d}_{\mathrm{th}}=7
$$

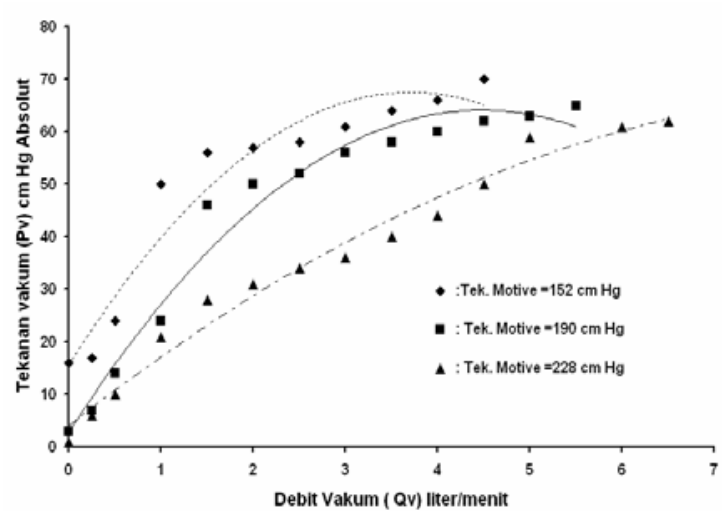

Gambar 10. Hubungan Tekanan Vacum $\left(P_{v}\right)$ terhadap Debit Aliran $\left(Q_{v}\right)$ pada $S_{n}=1$,

$$
\mathrm{L}_{\mathrm{th}} / \mathbf{d}_{\mathrm{th}}=\mathbf{5} \text {. }
$$

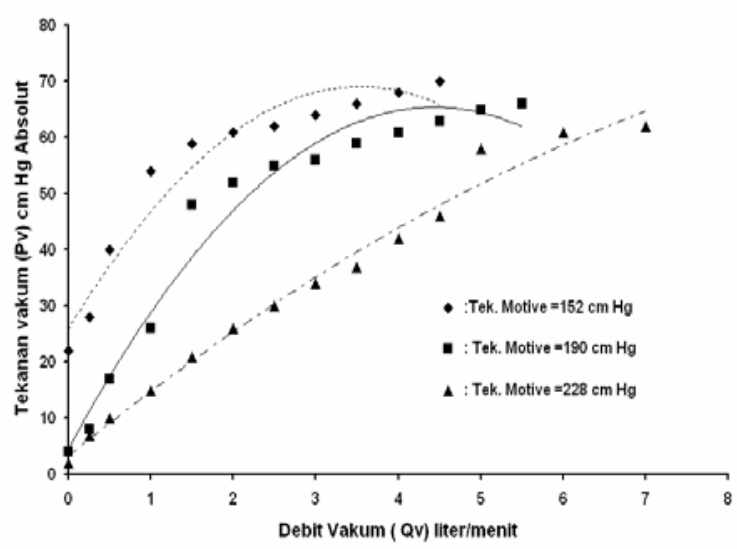

Gambar 11. Hubungan Tekanan Vacum $(P)$ terhadap DebitAliran $\left(Q_{v}\right)$ pada $_{n}=2, L_{t h} / d_{t h}=5$

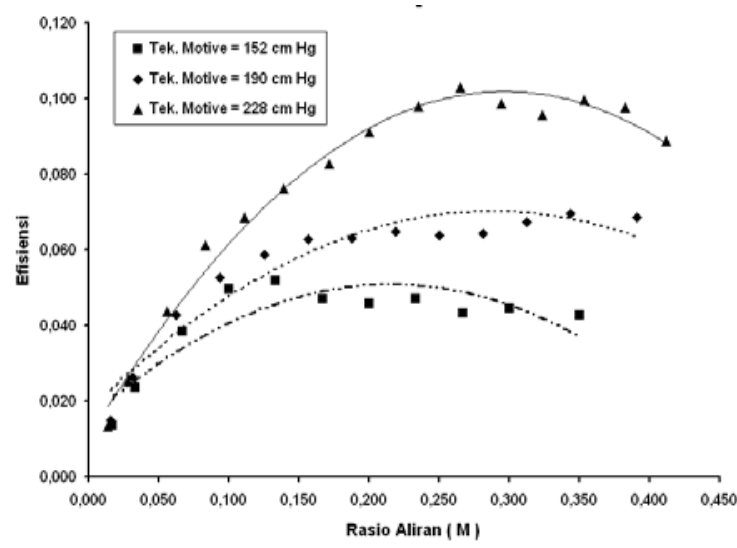

Gambar 12. Hubungan Efisiensi terhadap Rasio Aliran (M) pada $S_{n}=1, L_{t h} / d_{t h}=9$

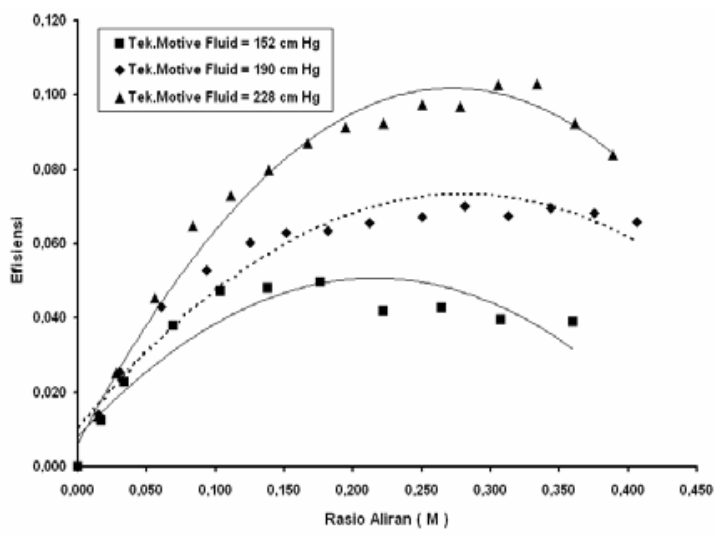

Gambar 13. Hubungan Efisiensi terhadap Rasio Aliran (M) pada $S_{n}=1.5, L_{t h} / d_{t h}=9$ 


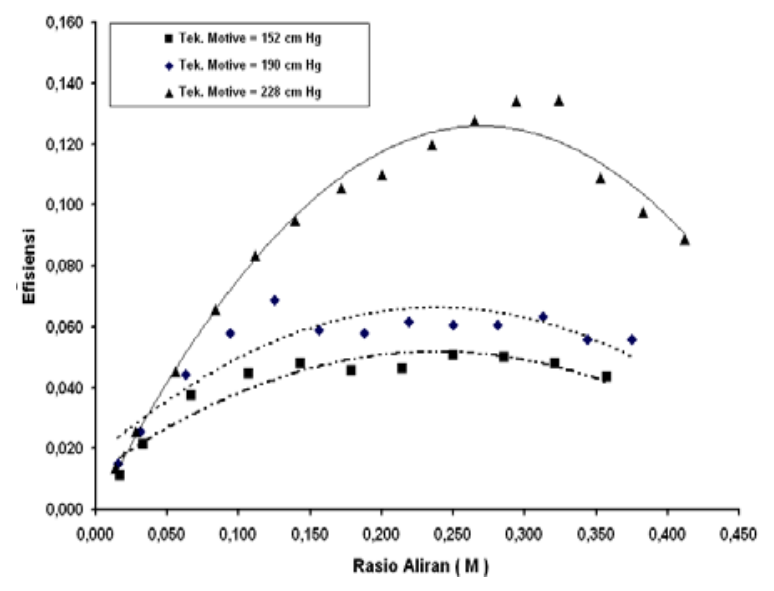

Gambar 14. Hubungan Efisiensi terhadap

Rasio Aliran (M) pada $S_{n}=2, L_{t h} / d_{t h}=9$

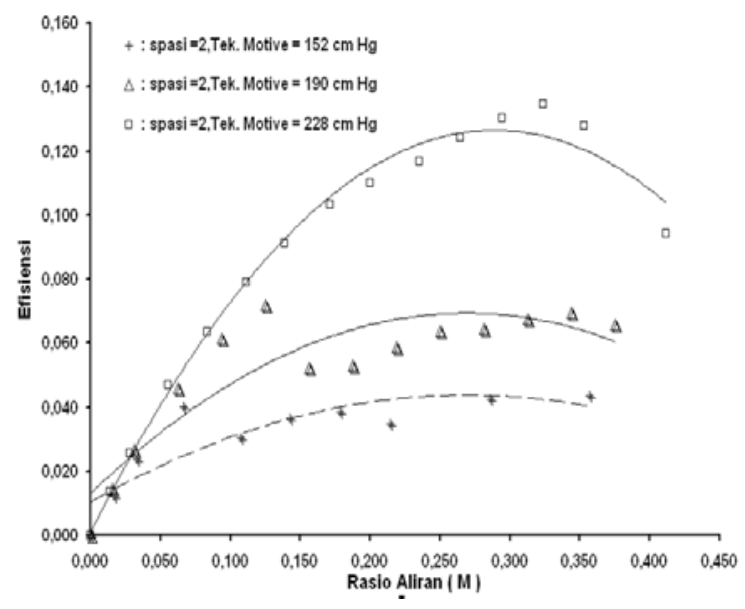

Gambar 15. Hubungan Efisiensi terhadap Rasio Aliran (M) pada $S_{n}=2, L_{\text {th }} / d_{\text {th }}=9$

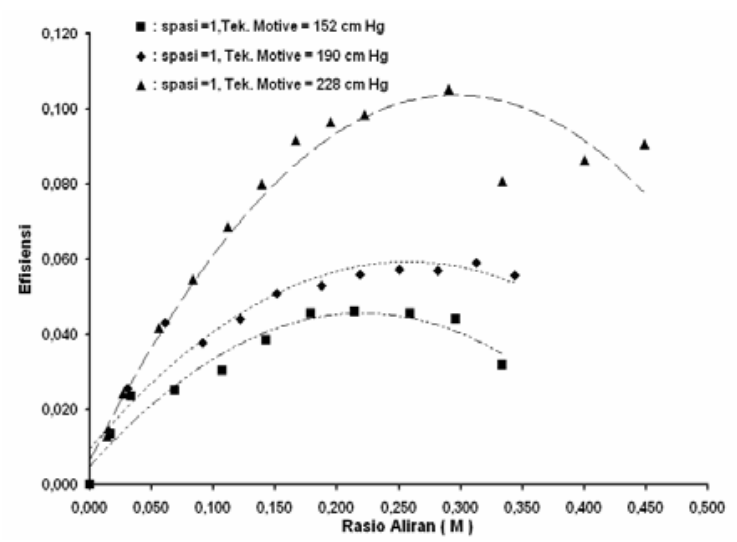

Gambar 16. Hubungan Efisiensi terhadap Rasio Aliran (M) pada $S_{n}=1, L_{t h} / d_{t h}=5$

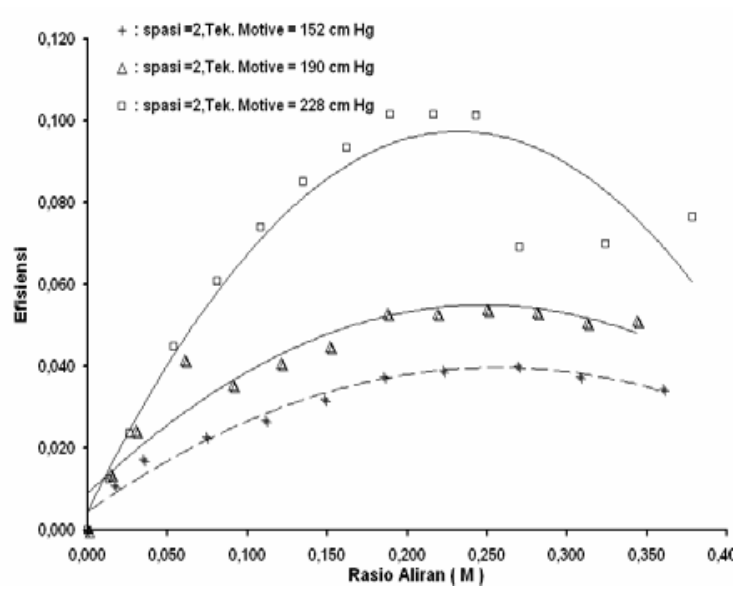

Gambar 17. Hubungan Efisiensi terhadap Rasio Aliran (M) pada $S_{n}=2, L_{t h} / d_{t h}=5$

Gambar 4 hingga Gambar 10, merupakan hasil pengukuran tekanan vakum dan debit aliran vakum dengan memvariasikan spasi nosel $\left(\mathrm{S}_{\mathrm{n}}\right)$ dan perbandingan diameter throat terhadap panjang troath $\left(\mathrm{L}_{\text {th }} / \mathrm{d}_{\mathrm{th}}\right)$. Gambar-gambar tersebut mempunyai pola-pola dengan kecenderungan yang sama, seperti yang tampak pada Gambar 18.

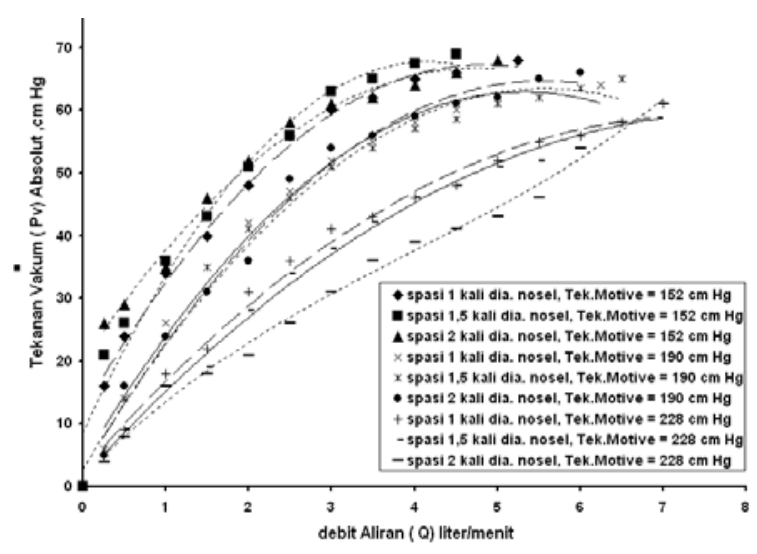

\section{Gambar 18. Pengaruh Perubahan $S_{n}$ Terhadap Debit dan Tekanan}

Pada Gambar 18. menunjukkan pengelompokan data, yang menunjukan bahwa perubahan spasi $\left(\mathrm{S}_{\mathrm{n}}\right)$ berkisar antara 1 hingga 2 kali diameter nosel tidak berpengaruh secara signifikan, pengaruh signifikan terjadi jika perubahan dilakukan pada tekanan motive. Tekanan motive yang lebih tinggi cenderung meningkatkan debit aliran terhadap tekanan vakum 
Gambar 10 hingga Gambar 17, merupakan hubungan efisiensi terhadap RasioAliran (M), dengan memvariasikan spasi nosel $S_{n}$ dan perbandingan diameter throat terhadap panjang troath $\mathrm{L}_{\mathrm{th}} / \mathrm{d}_{\mathrm{th}}$. Gambar-gambar tesebut mempunyai kecenderungan yang sama, seperti yang terlihat pada Gambar 19.

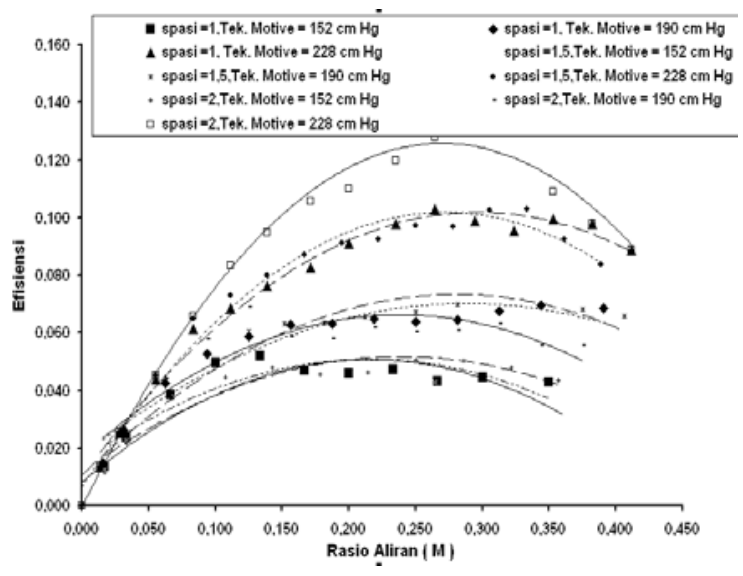

\section{Gambar 19. Pengaruh Perubahan $S_{n}$ terhadap Efisiensi Jet Pump}

Pada Gambar 19, menunjukkan pengelompokan data-data, dengan kecenderungan data-data mengelompok berdasarkan tekanan motive. Tekanan motive yang tinggi cenderung memberikan nilai efisiensi yang lebih baik pada semua tingkat rasio aliran( $\mathrm{M}$ ). Efisiensi menurun pada seluruh variasi tekanan motive terhadap penurunan rasio aliran (M).

Berdasarkan data-data hasil pengukuran dan pengolahan data, efisiensi maksimum dapat disajikan pada tabel.1. dengan berbagai variasi perlakuan.

Pada tabel 1. menunjukkan bahwa efisiensi maksimum terjadi pada tekanan motive $228 \mathrm{~cm} \mathrm{Hg}$, pada berbagai variasi $\mathrm{L}_{\mathrm{th}} / \mathrm{d}_{\text {th. }}$ Spasi nosel terhadap throat $\left(\mathrm{S}_{\mathrm{n}}\right)$. Perubahan panjang throat menunjukkan pengaruhnya terhadap efisiensi. $\mathrm{L}_{\mathrm{th}} / \mathrm{d}_{\text {th }}=9$, memberikan angka-angka efisiensi terbesar yaitu $13,5 \%,\left(S_{n}\right)=2$. Kecenderungan penurunan efisiensi maksimum pada tekanan motive $\left(\mathrm{P}_{\mathrm{m}}\right)=228 \mathrm{~cm} \mathrm{Hg}$, dan $\mathrm{S}_{\mathrm{n}}=2$ terhadap $\mathrm{L}_{\mathrm{th}} / \mathrm{d}_{\mathrm{th}}$, menunjukkan bahwa penurunan efisiensi akan terkorelasi terhadap berkurangnya
Tabel 1. Efisiensi Maksimum pada Berbagai Variasi

\begin{tabular}{|c|c|c|c|r|}
\hline$\underline{\mathbf{L}}_{\text {th }}$ & $\mathbf{P}_{\mathbf{m}}$ & \multicolumn{3}{|c|}{ Variabel } \\
\cline { 2 - 5 } $\mathbf{d}_{\mathbf{t h}}$ & $(\mathbf{c m ~ H g})$ & $\mathbf{S}_{\mathbf{n}}$ & $\mathbf{M}$ & \multicolumn{1}{|c|}{$\boldsymbol{\eta}$} \\
\hline \multirow{4}{*}{9} & 152 & 1 & 0,133 & 5,2 \\
\cline { 2 - 5 } & 190 & 1 & 0,391 & 6,9 \\
\cline { 2 - 5 } & 228 & 2 & 0,324 & $\mathbf{1 3 , 5}$ \\
\hline \multirow{4}{*}{7} & 152 & 2 & 0,357 & 4,0 \\
\cline { 2 - 5 } & 190 & 2 & 0,344 & 7,0 \\
\cline { 2 - 5 } & 228 & 2 & 0,294 & $\mathbf{1 3 , 4}$ \\
\hline \multirow{4}{*}{5} & 152 & 1 & 0,179 & 4,6 \\
\cline { 2 - 5 } & 190 & 1 & 0,313 & 5,9 \\
\cline { 2 - 5 } & 228 & 2 & 0,189 & $\mathbf{1 0 , 1}$ \\
\hline
\end{tabular}

angka $\mathrm{L}_{\mathrm{th}} / \mathrm{d}_{\mathrm{th}}$. Ditinjau dari derajat kevakuman sisi sekunder, penurunan efisiensi ini diikuti dengan tingkat kehampaan yang meningkat berdasarkan angka pada variabel rasio aliran (M) yang cenderung menurun terhadap menurunnya angka $\mathrm{L}_{\mathrm{th}} / \mathrm{d}_{\mathrm{th}}$.

Efisiensi yang diperoleh dari penelitian dengan fluida sekunder berupa udara memberikan angka yang relatif rendah dan tidak lebih dari 13,5\%, jauh lebih rendah dibandingkan terhadap jet pump dengan fluida sekunder berupa cairan. Hal ini diakibatkan oleh sifat fisis udara yang mempunyai massa jenis yang rendah dan pada tingkat kevakuman absolut semakin rendah cenderung menurunkan efisiensi diakibatkan sifat udara yang kompresibel sehingga mempengaruhi konversi momentum yang terjadi pada ruang pencampur dan rendahnya viskositas fluida sekunder (Stefanof, 1957)

\section{KESIMPULAN}

Berdasarkan hasil penelitian yang dilakukan, diambil kesimpulan sebagai berikut :

1. Efisiensi jet pump yang digunakan sebagai pompa vakum dengan variasi $\mathrm{L}_{\text {th }} / \mathrm{d}_{\text {th }}$ bervariasi 9,7, dan 5 , $\mathrm{S}$, bervariasi 1, 1.5, dan 2, serta tekanan Motive bervariasi $228 \mathrm{~cm}$ Hg, 190 cm Hg, 152 cm Hg, diperoleh efisiensi maksimum terjadi pada tekanan 
motive $228 \mathrm{~cm} \mathrm{Hg}, \mathrm{S}_{\mathrm{n}}=2$, dan $\mathrm{L}_{\mathrm{th}} / \mathrm{d}_{\mathrm{th}}=7$, yaitu sebesar 13,5\%.

2. Pengaruh perubahan spasi nosel hingga dua kali diameter penampang nosel tidak berpengaruh secara siknifikan terhadap efisiensi jet pump, pada variasi perubahan yang dilakukan.
3. Perubahan siknifikan terjadi dengan perubahan tekanan motive, meningkatnya tekanan motive hingga $228 \mathrm{~cm}$ Hg dari 152 cm Hg, meningkatkan efisiensi pada seluruh variasi.

\section{DAFTAR PUSTAKA}

Karassik. J.I, Krutzsch. W.C., Fraser.W.H.,1976. Pump Hand Book, p.4.1-4.25., McGrawhillBook Company, New York.

Sanger, N.L.,1970, An Experimental Investigation of Seveal Low Area-Ratio Water Jet Pump, Journal of Basic Engineering.

Stepanoff, A.J,1957, Centrifugal and Axial Flow Pump, ${ }^{\text {nd }}$ ed, p 402-424, John Wiley \& Sons, Inc, New York. 